\title{
La consciencia de sí y del mundo bajo los procesos de movilidad transcultural: la lectura de la novela memorial Solo queda saltar (2018), de María Rosa Lojo
}

\author{
Maria Josele Bucco Coelho ${ }^{1}$
}

Resumen. Los procesos de movilidad transcultural y migratoria se refieren a los desplazamientos caracterizados por la desterritorialización de los individuos de su comunidad de origen y su posterior inserción en una nueva comunidad cultural. Según Bernd (2013), tales movimientos engendran una inestabilidad en las fronteras geopolíticas, étnicas, sociales y de género que obligan la formulación de plataformas de acogimiento para los nuevos paisajes culturales que van siendo escudriñados a partir de la diferencia y de la diversidad. En ese proceso, muchas veces brutal, orbitan los distintos matices identitarios de quienes necesitan constituirse intersticialmente. Así, a partir de esas premisas, este estudio busca comprender, por medio del análisis de la obra Solo queda saltar, de María Rosa Lojo, la trayectoria doble/múltiple de la formación de la conciencia de sí y del mundo, buscando distinguir, apuntar y detallar la formación de subjetividades constituidas de forma multiterritorial, geográfica y simbólicamente. Al considerar la obra como una novela memorial, se busca, de esta manera, contribuir a la comprensión de la influencia de los procesos migratorios vividos en la comunidad literaria del Atlántico Sur en los comienzos del siglo XX y su importancia en la dinámica de producción literaria contemporánea.

Palabras clave: movilidades culturales; literatura y territorialidad; novela memorial; literatura contemporánea; María Rosa Lojo.

[en] Awareness of oneself and of the world under the processes of transcultural mobility: a reading of the memorial novel Solo queda saltar (2018), by María Rosa Lojo

\begin{abstract}
The processes of transcultural and migratory mobility refer to the displacements characterized by the deterritorialization of the individuals, of their community of origin and their subsequent insertion into a new cultural community. According to Bernd (2013), such movements engender instability in the geopolitical, ethnic, social and gender frontiers that force the formulation of shelters for the new cultural landscapes, which are being investigated from difference and diversity. In that process, often brutal, orbit the different identity nuances of those who need to be interstitially constituted. Thus, based on these premises, this study seeks to understand, through the analysis of the narrative Solo Queda Saltar, by María Rosa Lojo, the multiple trajectory of the self-awareness constitution and of the world, seeking to distinguish, aim and detail the formation of subjectivities constituted in a multi territorial manner, geographically and symbolically. Considering the narrative as a memorial novel, it is sought, in this way, to contribute to the understanding of the influence of the migratory processes, lived in the South Atlantic literary community in the early twentieth century and its importance in the dynamics of contemporary literary production.
\end{abstract}

Keywords: cultural mobility; literature and territoriality; memorial novel: contemporary literature; María Rosa Lojo.

Sumario. 1. Introducción. 2. La novela memorial o de familia: el caso de Solo queda saltar (2018). 3. La conciencia de sí y del mundo en la narrativa memorial. 4. El camino hacia el salto. 5. El papel de las movilidades culturales en la narrativa lojiana. 6. Consideraciones finales.

Cómo citar: Coelho, M.J.B. (2021) La consciencia de sí y del mundo bajo los procesos de movilidad transcultural: la lectura de la novela memorial Solo queda saltar (2018), de María Rosa Lojo, en Anales de Literatua Hispanoamericana 50, 63-71.

\footnotetext{
${ }^{1}$ Universidade Federal do Paraná, Paraná. Brasil

Email: joselebucco@gmail.com
} 
En el borde del mundo, en el borde de la vida, solo queda saltar. Esas alas que llevamos en secreto, cuerpo adentro, se abren únicamente cuando nos atrevemos a caer.

(Lojo, 2018: 25)

\section{Introducción}

Publicada en 2018, la novela Solo queda Saltar, a pesar de ser considerada como literatura juvenil, concentra los grandes ejes de la narrativa lojiana: la resignificación del pasado histórico y literario, los trabajos de la memoria y del olvido fracturados por el exilio impuesto y heredado, el impacto de las movilidades culturales en la construcción identitaria y en la búsqueda para consolidar una territorialidad literaria. Por medio de un lenguaje leve y sutil, la trama concentra tales postulados por medio de la lucha visceral de dos hermanas Celia e Isolina- por integrarse a una nueva comunidad cultural tras una inmigración impuesta por la guerra civil española.

Como "dos muñequitas atrapadas en un globo de cristal luminoso" (Lojo, 2018: 15), las niñas de luto llegan a Chivilcoy, con la última ola de inmigrantes, tras enterrar a sus muertos. Pareciendo viejas (por los vestidos negros) ellas buscan el amparo de un tío de su familia española, del que tenían hasta entonces solo retratos. Él mismo, habiendo emigrado antes, enfrentará la llegada de las dos niñas como el retorno a sí mismo, a los vínculos familiares y a su identidad fracturada, igualmente, por la distancia.

Dividida en dos partes, esta novela memorial llevará a los lectores, en un primer momento, al pasado de Celia, a sus pesadillas recurrentes tras un olvidado intento de violación y a su entrada en la vida adulta, a su proceso de madurez. En aquel 1948, los recuerdos en el diario de la joven que estaba casi cumpliendo dieciocho años, retratan la lucha de las mujeres por consolidarse como sujetos y la mezcla de sus dolores personales con la historia de la nación argentina y sus conflictos políticos y culturales.

En un segundo momento, fijado en el tiempo de la escritura de la novela, 2018, los lectores van a encontrarse con los conflictos de la vejez de Isolina, la hermana menor. Será ese el personaje que, a partir de sus rememoraciones, permitirá concluir el rompecabezas memorial que compone la trayectoria de las dos inmigrantes. Los vacíos y grietas abiertas en la primera parte de la trama son rellenados cuando Isolina, en su retorno a la tierra de origen, se propone una misión:

Hoy, en Fisterra, de donde partimos hace tanto tiempo, tengo una misión. O varias misiones. La primera es ponerme a recordar y a escribir mi recuerdo. Aunque no lo haga tan bonito como mi hermana, que siempre tuvo el don de las letras y la vocación de su estudio. (Lojo, 2018: 103)

Así, considerando el recorrido hecho por las dos hermanas, que culmina, en ambos casos, en la conciencia de sí y del mundo en distintas fases de la vida, este estudio tiene el objetivo de escudriñar la importancia de la transmisión generacional y de la reapropiación genealógica y familiar para la consolidación de la memoria cultural. En ese proceso, al describir las características de la novela memorial, entendida como un recurso que permite acceder al pasado, tomándolo como principio organizador de la identidad de los personajes en distintas modalidades, se buscará demostrar la importancia de los procesos de movilidad transcultural y su incidencia directa en la producción literaria de María Rosa Lojo.

\section{La novela memorial o de familia: el caso de Solo queda saltar (2018)}

Para Vargas Llosa, la literatura constituye uno de los más significativos legados de la colectividad humana. El escritor defiende que la expresión literaria y, en especial la novela contemporánea, establece un vínculo fraterno entre los seres humanos, obligándolos a dialogar y volviéndolos conscientes de los sustratos comunes que trascienden el tiempo. En ese proceso, continúa Vargas Llosa, es posible apropiarse de la realidad, arrojarse al pasado y hermanarse con otros que "se han entusiasmado y soñado" (2009: 22), engendrando así, una conexión integradora que amplía la conciencia de sí y del mundo. Ese razonamiento de Vargas Llosa, que sigue provocativo al afirmar que la ficción posibilita a las comunidades fugarse de las prisiones de la realidad y abrirse a los aspectos desconocidos y secretos de la condición humana, facilita la comprensión del crecimiento de las novelas memoriales en el siglo XXI.

Esas narrativas, también conocidas como novelas de familia o novelas de filiación, se establecen en la primera década del siglo XXI. Sin embargo, sus primeras manifestaciones ocurren todavía a fines del siglo 
XIX y comienzos del siglo XX, cuando surgen y tienen gran éxito las sagas y novelas genealógicas. Los Buddenbrook de Thomas Mann, de 1901, está considerado como uno de los principales representantes de esas caudalosas narrativas que se concentran en describir, a partir de una escritura realista, la evolución de una familia a través de varias generaciones.

Para Massaud Moises, esos relatos de historias de familias que mezclaban hechos ficcionales y verídicos (1999), empiezan a declinar en la segunda mitad del siglo XX. De forma totalizadora, tales narrativas buscaban representar, a partir de un narrador omnisciente y de un orden cronológico lineal, la degradación y la decadencia de una familia a lo largo de varias generaciones. Vale la pena destacar, de acuerdo con Bernd y Soares (2016: 407), que el gusto por ese tipo de narrativa no desaparece, sino que es incorporado a otros soportes, como el televisivo. El principal cambio en ese género narrativo va a ocurrir en comienzos del siglo XXI, con el fuerte crecimiento de la autoficción y el resurgimiento de la novela memorial. Según las autoras, pese a la relación existente entre tales producciones literarias, se hace necesario distinguir las principales diferencias y transformaciones que el género ha incorporado:

La novela memorial está profundamente asociada a la recuperación de la memoria cultural, revelando preocupación con la temática de la ascendencia y de la ancestralidad. [...] El objetivo deja de ser la interioridad (el "yo" narrador) para ser la anterioridad - centrado en la historia de los ascendientes, el narrador acaba relatando su propia historia y destacando su papel de heredero de sus ancestros o recusándose a establecer el continuum con las generaciones que le preceden. (Bernd y Soares, 2016: 408) ${ }^{2}$

Desde esa perspectiva, Bernd y Soares (2016: 409) destacan que la novela memorial ${ }^{3}$ se convierte en un subterfugio para hablar de sí mismo y de esa especie de herencia parental, buscando continuarla o romperla. El narrador, tal como un investigador, arqueológicamente, busca en los vestigios memoriales, los rastros dejados por el olvido para reconstituir la vida de sus ancestros. Esa investigación lo llevará a una comprensión de su propia imagen, ayudándole a (re)pensar su identidad.

En ese proceso, ese narrador es libre de decidir lo que va a elegir como su herencia. (Oz y Salzberg, 2015: 173). Esa elección, sin embargo, puede ser hecha más allá de una generación a otra (padres, abuelos, bisabuelos), llegando a ancestros antiguos, como los patriarcas.

Otro punto a ser destacado en las novelas memoriales es el papel de la transmisión. Según Candau (2014), la preservación de la memoria de los ancestros es muy importante, pues es lo que permite mantener la propia identidad. Así, el acercamiento a las trayectorias de vida de los antepasados propicia que el narrador resignifique y/o (re)construya su presente. La transmisión, por lo tanto, se vuelve vital y va a garantizar la sobrevivencia de la comunidad por medio del establecimiento de un continuum que no es fundamentalmente religioso ni biológico, sino verbal y cultural (Bernd y Soares, 2016: 411).

\section{La consciencia de sí y del mundo en la narrativa memorial}

En la novela de María Rosa Lojo, Solo queda saltar, publicada en 2018, las dos narradoras -Celia e Isolinabuscan comprender, en distintas etapas de sus vidas el vínculo con sus raíces ancestrales. La trama de esta novela memorial describe el regreso a un pasado que ocurre, inconteniblemente, como una estrategia de sobrevivencia, un camino por el que es imposible recular, pero que exige, de ambas narradoras, el necesario coraje. De allí, la imagen que da título a la obra, la acuciante necesidad de saltar, de lanzarse en búsqueda de sí y de la herencia memorial que permitirá a las dos integrarse a una tradición, a una comunidad cultural.

Interesante percibir que, en el caso de esta obra, la estructura narrativa se convierte ella misma en un rastro, un trazo memorial. Entendido como una presencia-ausencia, este rastro/trazo/vestigio puede ser tanto una marca física como simbólica.

Orbita alrededor de ese concepto una terminología variada. Derrida ha usado por primera vez la expresión 'trazo' para designar la presencia de una ausencia o una presencia que se desplaza. Otros teóricos revisitaron el concepto. Entre otros, Paul Ricoeur (2007: 16), por ejemplo, utiliza el término 'vestigio' y lo considera

\footnotetext{
${ }^{2}$ Todos los fragmentos citados en ese texto fueron traducidos por la autora de este trabajo.

${ }^{3}$ Se hace importante señalar que el término 'novela familiar' fue usado por Freud para designar los procesos imaginativos creados por los individuos con el objetivo de crear un vínculo distinto con la familia.
} 
como la marca dejada por un timbre sobre la cera caliente. Hay una marca, ella está presente, pero el timbre ya no está, es una señal de un pasado que solo se puede intuir.

En la novela Solo queda saltar, conforme se ha apuntado, la estructura dividida en dos partes, con narradoras y tiempos narrativos distintos, plantea una interesante perspectiva. Normalmente, en las novelas memoriales, la trama es desencadenada por algún tipo de vestigio, objeto o lugar de memorial: el narrador buscará en retratos, cajas y objetos antiguos las marcas de la historia de sus ancestros que fueron apagadas o que se presentan borradas.

El diario de Celia, que corresponde a los veintitrés primeros capítulos, será el vestigio memorial donde la segunda narradora Isolina, pasados casi setenta años, va a buscar las respuestas para inserirse en la herencia familiar: "En el mismo cajón donde estaba el cuaderno de Celia, el que me confió para traerlo a Fisterra, encontré otras páginas, sueltas, fechadas en 1980. Aunque no me habló de ellas, sin duda quiso que las viera" (Lojo, 2018: 140).

El cajón, conforme a lo descripto en el fragmento, contiene los objetos dignos de memoria donde Isolina encuentra el diario que compone la primera parte de la novela además de otros vestigios y rastros memoriales que Celia, la hermana mayor, le encargara. Son estos vestigios los que le permiten a ella completar los hechos pasados y traumáticos del proceso de inmigración. Por medio de la lectura de los apuntes de la hermana, Isolina descubre los dolores y desafíos íntimos que ha sufrido y enfrentado su hermana y, de alguna manera, los integra a sí misma, consolidando así el legado familiar, una especie de herencia que conecta los dos mundos: el de partida y el de vuelta, garantizando a ambas el sentimiento de pertenecer a un linaje:

Nosotras fuimos de los últimos en emigrar a América. Será de los que marcharon en la época de Franco a Alemania o a Suiza o a Inglaterra. Trabajaban en lo que podían y todo lo que ahorraban era para volver aquí de viejos, y vivir como aquellos que los habían despreciado. (Lojo 2018: 128)

Como se puede observar, las memorias individuales que constituyen la trayectoria de Celia e Isolina se conectan con esa representación más amplia de un linaje, de todos los que, de forma espontánea o perentoria, se desplazaron en búsqueda de otra vida lejos de la dictadura franquista. Esa conexión fundada en memorias compartidas es muy significativa para la construcción identitaria, pues, conforme defiende Candau, la representación de la memoria debe ser entendida como "un enunciado que miembros de un grupo van a producir respecto a una memoria hipotéticamente común a todos los miembros del grupo" (Candau, 2011: 24).

En ese contexto, es importante insistir en que la novela Solo queda saltar constituye un dispositivo que preserva la memoria cultural de esa comunidad marcada por los procesos de movilidad, siendo responsable, igualmente, por la transmisión intergeneracional de los sujetos narradores.

Isolina e Celia, por lo tanto, al recordar su pasado, tejen una narrativa familiar que les permite conectarse con ese grupo de inmigrantes. Ese juego, conforme exploran Bernd y Soares (2016: 412), es propio de la novela memorial y, muchas veces, tiene su origen en padres ausentes, valores obsoletos, fallas, faltas o grietas que el narrador busca restituir por medio de la re(construcción) de la historia de su ascendencia. En la narrativa, la grieta abierta por el proceso de movilidad es suturada por medio de la consciencia de sí, el salto que permite a Celia e Isolina dar continuidad al patrimonio memorial heredado. Ese salto, sin embargo, ocurre de forma escalonada y gradual.

\section{El camino hacia el salto}

Considerando que el tiempo narrativo de la segunda parte de la novela coincide con la lectura que Isolina hace de los escritos de Celia, se puede afirmar que el salto por ella realizado -hacia la conciencia de sí misma- se da en la vejez.

Celia, su hermana, décadas antes, previó qué papel desempeñaría en ese proceso: "Yo abro el camino. Me seguirá Isolina" (Lojo, 2018: 58). Así, al confiar sus papeles a la hermana menor, para que los llevara a Fisterra, Celia compartió la clave que le ayudó a estar de pie frente a lo que quería ser:

Llevé un cuaderno de notas, o un diario, hace muchos años. Cuando cruzamos el mar y llegamos aquí. Ahora pienso que ese cuaderno era como un cayado de peregrino. Esos bastones de punta curva donde se apoyaron durante siglos los caminantes que marchaban a Santiago de Compostela. Desde todas partes de España y de Europa, por rutas con nombres de geografías reales o metafóricas, hasta alcanzar el centro donde encajaban las piezas sueltas de la realidad y se abrían, por fin, las puertas del destino. (Lojo, 2018: 140) 
La escritura de las memorias es, por lo tanto, la herramienta usada por Celia para garantizar la transmisión de su "herencia" a Isolina, el cayado que le permite, de forma gradual, disponer las piezas sueltas de su historia, descubrirse como mujer e integrarse a una nueva comunidad cultural que todavía es una incógnita a ser desvelada:

¿Es este país, Argentina, otro almacén donde se juntan cosas y seres que de otro modo jamás se hubieran reunido? Siento que todo es parte de un rompecabezas secreto y que una gran belleza está por sucederme. Soy un signo en un código, la letra de un mensaje donde me están escribiendo. (Lojo, 2018: 29)

Celia, por lo tanto, al pasar el cayado/diario a Isolina está garantizando que el principio organizador de sus identidades, el pasado familiar fracturado por la ruptura causada por la movilidad cultural, sea compartido y resemantizado. Esa herencia memorial es descripta a lo largo de los veintitrés primeros capítulos y demuestra cómo Celia fue comprendiendo e incorporando los nuevos espacios y los constructos culturales:

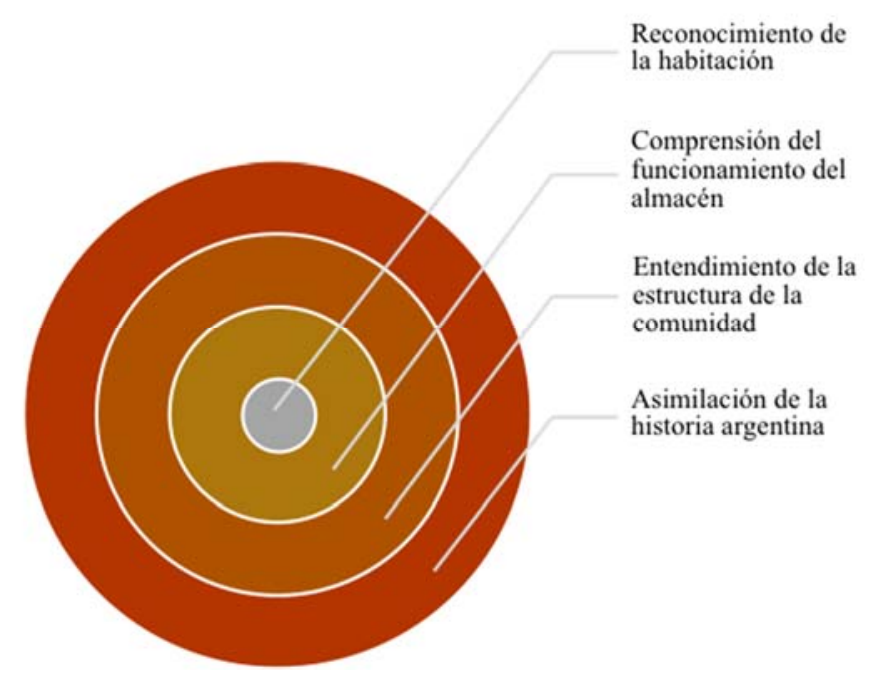

Infografía 01: Celia y los escalones de la consciencia de sí y del mundo

Conforme se puede observar, el camino realizado por Celia hacia su salto, símbolo de esa conciencia de sí y del mundo, es hecho de forma gradual. En una especie de círculo creciente, ella va reconociendo los espacios personales, familiares y comunitarios. Ese proceso de comprensión de la realidad le permite, simultáneamente, acceder a esferas de su intimidad que estaban mantenidos en la oscuridad:

-Todos sabían lo que pasó. Hasta usted, tío, desde aquí. Menos yo.

-El médico dijo que no te lo mentasen si tú no lo recordabas.

-Y nadie quería acordarse.

-Quién lo querría, cuando nada puede hacerse. Cuando no hay justicia que te escuche ni derechos que defender (Lojo, 2018: 89).

La memoria individual, conforme se puede comprobar, se amplía, revelando las circunstancias históricas que atraviesan las dificultades enfrentadas por Celia. Para Robin (1989) esa es una de las características de la novela memorial, anclada en la valoración de lo sensible y de lo simbólico. Por medio de la recuperación de la memoria de los antepasados, emerge la memoria cultural de determinado período histórico. Por ello, habiendo sufrido un intento de violación en un momento donde la justicia no puede ser accionada, la joven se reapropia de esas memorias de dolor, convirtiéndolas en un eje para la recomposición de sí. Celia comprende, finalmente, quién es. Más que eso, salta en dirección a quién será:

Por primera vez en tanto tiempo tengo piedad de mí y también de ellas: mi madre, mi abuela. Muertas de miedo, ocultándose, ocultándome. [...] Protegiéndome de un futuro que para nosotras siempre iba a empeorar.

Ese futuro dejó de existir y tengo otro. Me haré otro. (Lojo, 2018: 89) 
En esa esfera temporal de la narrativa, cuando finalmente Celia comprende su historia y puede decidir saltar hacia otra vida, Isolina todavía es una niña. A diferencia de Celia, ella se desplaza a América sin fantasmas, pesadillas o inseguridades. Está conforme con el viaje y decidida a encontrar en la nueva tierra a las Siniguales, criaturas con las cuales se identifica, que "no se parecen a nadie, sino a ellas mismas" y que no están en los cuentos, sino "en las rocas, al lado del mar" (Lojo, 2018: 51).

Viviendo libre y haciendo elecciones de vida con seguridad, sin importarle la opinión de los demás, Isolina crecerá con el apoyo familiar: "Tú eres la Sinigual, a miña nena - susurró -. Ya no hace falta que las busques más. Aquí no tendrás penas. Llegaste a casa” (Lojo, 2018: 51). Aparentemente, conforme se comprueba en la distancia que separa las dos partes de la narrativa, Isolina hará el salto hacia sí misma solamente en la vejez, con el acercamiento de la muerte.

Igual que Celia, ese salto es desencadenado por un proceso de movilidad. En ese caso, es el retorno a la tierra de origen, que la obliga a Isolina a (re)conocer e incorporar su linaje: "Es el pasado que vuelve a encontrarse con mi vida" (Lojo, 2018: 128).
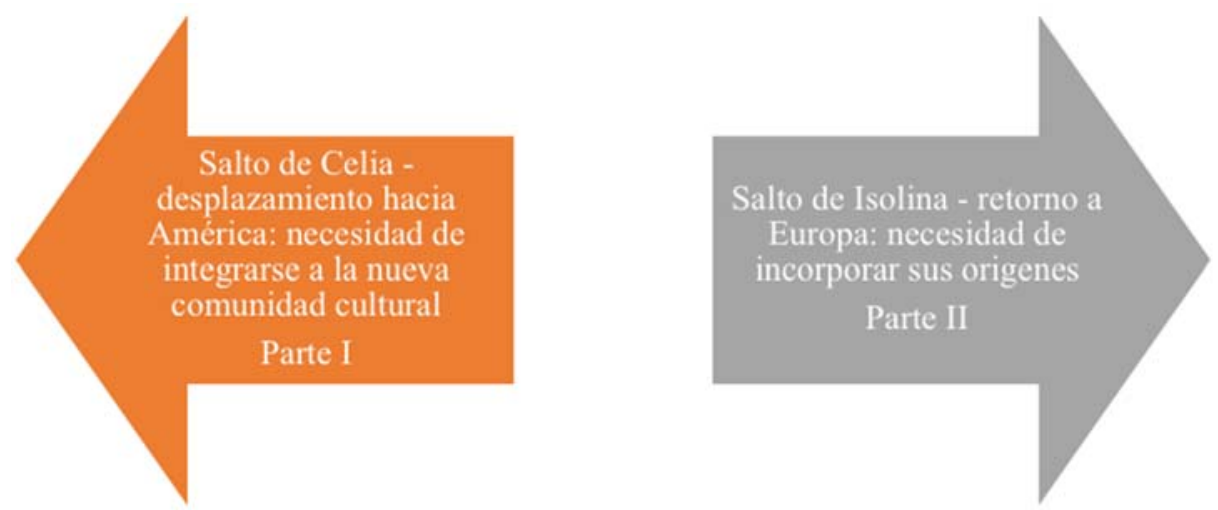

Infografía 02: Las movilidades y los procesos de concienciación

Los dos saltos permiten a las narradoras posicionarse en el mundo y, principalmente, situarse como sujetos con una identidad en continuo proceso de construcción y desconstrucción. Así lo confirma Isolina, leyendo los escritos de Celia: "vivo mi vida en círculos crecientes, que se dibujan sobre las cosas. Quizá no llegue a completar el último, pero voy a intentarlo" (Lojo, 2018: 143).

El continuun establecido por medio de las memorias compartidas y plasmadas en la escritura, sutura las identidades fracturadas por los procesos de movilidad. Permiten, así, a las narradoras elegir la herencia a la cual desean filiarse y garantizan la integración al momento presente:

Como un rompecabezas que se arma de golpe, cuando ya se han perdido las esperanzas de comprender, lo entiendo.

Yo soy el vaivén.

Cuando me voy, nada dejo, porque todo viaja conmigo.

Soy la casa sin anclas, soy mi propia barca que cruza los abismos llevando la memoria de todas las orillas.

Migramos para sobrevivir. (Lojo, 2018: 149)

Al completar su salto en relación a la comprensión de sí misma y del mundo, Isolina concientiza que la movilidad es parte integrante de su identidad y es lo que la conecta con la familia, con la comunidad y con la propia historia. Conforme explican Oz y Salzberger (2015), reconstruyendo la trayectoria de los antepasados, los sujetos logran la construcción de un lugar para sí. Recurriendo a los vestigios y trazos memoriales que rescatan la sensibilidad del convivio familiar, descartado por los discursos oficiales, las narrativas memoriales se convierten en una especie de imperativo, un deber primario de la memoria humana-familiar, tribal, nacional- que permite a los sujetos preservar la memoria cultural.

\section{El papel de las movilidades culturales en la narrativa lojiana}

Tomadas como la capacidad de los sujetos de moverse entre dominios culturales distintos, hecho que se inscribe en "formas literarias de la contemporaneidad que conjugan, simultáneamente, más de un horizonte cultural" (Bernd, 2010: 14), las movilidades culturales asumen diferentes matices que obligan al 
rompimiento con los tradicionales puntos de referencia étnicos, lingüísticos y nacionales que son, casi siempre, responsables por la noción de pertenecer a una comunidad 'imaginada'.

Además de eso, las movilidades culturales despiertan cuestionamientos en relación a la manera como los sujetos desplazados conforman nuevas redes y reinventan un estar-en el-mundo que excede la idea de cultura y nación unificada, constituyendo, por lo tanto, el eje basilar de las comunidades literarias y de las estéticas glocales ${ }^{4}$. De acuerdo con Bernd, es posible clasificar las movilidades en cinco grandes categorías:

-Movilidades migratorias transculturales: designan los desplazamientos impuestos/vividos/sufridos por comunidades culturales en medio de procesos de inmigración y presuponen el desencadenamiento de pasajes y transferencias culturales. Ese tipo de movilidad puede ocurrir también dentro de la propia comunidad cultural, cuando los individuos son compelidos a la marginalidad o subalternidad y congrega movimientos de deriva, desplazamiento, des(re)territorialización, errancia, nomadismo, tránsito y transnacionismo.

-Movilidades memoriales e intersubjetivas: designan los movimientos que conjuran, de acuerdo con Bernd (2010), "las ecuaciones de la propia memoria donde el olvido se constituye en aspecto integrante del proceso mnemónico" (Bernd, 2010: 18). En ese espacio intersticial y subjetivado que congrega la autoficción, memoria e imaginario son encontrados vestigios culturales que determinan, por una parte el trabajo, el deber y los abusos de la memoria, y, por otra el olvido, lo no-dicho, el silencio y los mecanismos activadores de memorias e imaginarios reinventados.

-Movilidades transaccionales: designan los desplazamientos que cargan en sí la idea de "ultrapasar, de ir más allá, de pasar a través de" y envuelven transposiciones de sentido que "operan en nivel simbólico, [...] resultado de innúmeras trapazas y negociaciones con el lenguaje” (Bernd, 2010: 21). Las movilidades transaccionales (metáfora, movilidad lingüística, traducción, transportación, variación) señalan la experiencia del individuo que, por seguir en constante tránsito, vivencia la falta/dificultad de identificación y busca nuevas formas de expresión que puedan retratar esa condición.

-Movilidades espaciales (del imaginario de las metrópolis): designan las circulaciones urbanas y la experiencia del flaneur. Esas movilidades se refieren, específicamente, al movimiento espacial y describen la experiencia de transitar en el caos urbano, de hacerse parte de la multitud, perdiéndose constantemente en el flujo de las grandes ciudades.

-Movilidades desviantes: designan los "mecanismos de transgresión de la norma y la resistencia por la astucia y no por la fuerza" (Bernd, 2010: 22). Estas movilidades (braconaje ${ }^{5}$, desvío y liquidez ${ }^{6}$ ) se organizan en medio de territorios prohibidos y hacen referencia a los mecanismos usados como estratagemas de transgresión dentro de las comunidades culturales.

En el caso de la novela Solo queda saltar, están imbricadas dos categorías de movilidad: las memoriales e intersubjetivas (ya extensamente explotadas en este estudio) y las movilidades transculturales (cuando los personajes Isolina y Celia han sufrido un proceso migratorio forzado, violento, impuesto por las condiciones nefastas de la guerra civil española). En este sentido, conforme se ha defendido anteriormente, la movilidad transcultural se instaura no solo en lo territorial, físico, sino también en los desplazamientos de origen ontológico y simbólico, instituyendo un imaginario y una consciencia identitaria que se sabe transcultural, transnacional y hasta postnacional.

${ }^{4}$ Las estéticas glocales se refieren a las producciones literarias que subliman y (re)presentan un imaginario en el cual se vislumbra la constitución de identidades atravesadas por referenciales culturales múltiplos. De fondo dialógico y decolonial, tales estéticas son tensionadas por el proceso de globalización y crecen en las zonas de contacto donde, inevitablemente, los sujetos comparten una doble - sino múltiple - consciencia caracterizada por el diálogo difícil entre culturas distintas. En estas zonas de contacto, las prácticas literarias reflejan esa necesidad de vivir en lenguas, historias e identidades que cambian constantemente. Defendemos, en ese sentido, que la producción literaria de María Rosa Lojo es un ejemplo de estética glocal.

Más información: Maria Josele Bucco Coelho (2018). "Práticas literárias e territorialidade: estéticas glocais", en Literatura e práticas culturais: linguagens e intercâmbios. São Paulo: Pontes.

${ }^{5}$ Concepto desarrollado por el estudioso canadiense Simon Harel (braconnage en francés o poaching en inglés). En español, también puede ser traducido por caza furtiva o caza ilegal, pero no engloba toda la propuesta semántica del término original. Por eso, en este trabajo, optamos por utilizar el neologismo "braconaje" para hacer referencia de manera más directa a braconnage y braconnier tal como los utiliza Harel.

${ }^{6}$ El concepto de liquidez, propuesto por el teórico Zygmund Bauman, refiere la fluidez propia de los tiempos contemporáneos. La capacidad de interacción y movilidad intensificadas en la modernidad son incorporadas en la producción-recepción de las prácticas literarias, desestabilizando la triada clásica (un autor, una lengua, una literatura). Para más información sobre la relación de ese concepto con las movilidades culturales, consultar la obra: Zilá Bernd (2010). Dicionário de mobilidades culturais: percursos americanos. Porto Alegre: Literalis. 
En esa perspectiva, al fundar subjetividades que se constituyen de forma híbrida, las movilidades transculturales posibilitan e impulsan la existencia de diferentes expresiones estéticas. Tales expresiones se articulan por medio de la posibilidad del individuo de posicionarse en lugares de enunciación distintos, como una especie de ser/testigo que se constituye por medio de la coexistencia de referencias múltiples.

Tal postura exige, igualmente, la percepción, primera, de la existencia de una dimensión subjetiva que entiende el territorio como el producto de una apropiación/valoración simbólica de un grupo en relación al espacio vivido y exige la subversión de las fronteras tradicionales. Además de todo, presupone la defensa de que la experiencia del mundo y el proceso de significación ocurren en una semiesfera compartida por individuos que mantienen vínculos similares, pero que no siempre son reconocidos. En ese proceso, es importante señalar que la narrativa lojiana se caracteriza por el cruce de, por lo menos, tres culturas: la argentina, la castellana y la gallega:

[...] usted me preguntó sobre la familia y los orígenes, eso ha sido, para mí una clave de la escritura. [...] Y para mí eso fue tanto más importante debido a que yo tenía una tradición en el suelo donde había nacido, una tradición que mis padres no pudieran trasmitirme porque la ignoraban, ellos trasmitieron la propia, la tradición española, en dos vertientes, la castellana y la gallega, que son dos culturas distintas aunque estén dentro de un mismo estado nacional. Y...rescatar esas historias de familia para mí fue muy importante porque definía mi propia persona, quien era yo sobre este mundo y de donde había salido. (Lojo 22/04/2013, información verbal)

Así, en ese proceso argumentativo, la novela memorial de María Rosa Lojo se configura como parte de una práctica literaria glocal, pues sublima y (re)presenta un imaginario en el cual se vislumbra la constitución de identidades traspasadas por referenciales culturales múltiples, arraigados en una territorialidad que no es constituida necesariamente por una frontera únicamente espacial y que es tensionada, concomitantemente, por los múltiples procesos de movilidad. María Rosa Lojo, en la perspectiva defendida en este estudio, pertenece a una comunidad literaria instaurada en un espacio intersticial nacido en/de los procesos de movilidad cultural.

\section{Consideraciones finales}

Las comunidades literarias se estructuran en territorialidades simbólico-culturales y se fundan en la dinámica de articulación y rearticulación de sus actores, siendo, por lo tanto, definidas a partir del concepto de red ${ }^{7}$, según sostiene Enne (2004). En esta perspectiva, se estructuran como un paradigma a partir del cual es posible fraguar prácticas literarias específicas, resultantes de la apropiación simbólica de los individuos en relación al espacio vivido. En el caso de la obra analizada, están en el vértice de esas prácticas glocales, los intensos procesos de movilidad transcultural y migratoria, de los cuales María Rosa Lojo constituye un fuerte ejemplo.

La percepción de que las comunidades literarias engendran expresiones singulares es defendida por Palmero (2012) que considera la heterogeneidad latinoamericana como el centro difusor de esa dinámica. Ella entiende que los desplazamientos instauran un nuevo locus de enunciación donde es posible estructurar tanto nuevos marcos de referencia críticos e historiográficos como poéticas de la escritura.

Tales poéticas de escritura, aquí entendidas como estéticas glocales (Coelho, 2018) constituyen un espacio de producción-recepción que sufre y se apropia del impacto de los procesos migratorios en la producción artística y literaria. Centradas en los intercambios culturales exigen, por supuesto, una nueva percepción que resulta en un abordaje que responde a los localismos.

\footnotetext{
El concepto de red es ampliamente utilizado por las ciencias sociales, en especial por la antropología. Según Enne (2004), hay una pluralidad de acepciones en relación a ese concepto, pero todas están centradas en la idea de que una red la constituyen las relaciones de actores. Conforme sostiene ese autor, "as sociedades complexas não podem ser percebidas a partir de uma dicotomia entre a estrutura social e a estrutura cultural, pois os fluxos de informações e ideias, sua materialização e distribuição, são fatores ordenadores e reordenadores das composições sociais, fazendo com que estas sejam marcadas por uma constante mobilidade. Segundo ele, a grande preocupação dos atores sociais envolvidos na construção das sociedades complexas diz respeito à administração desses fluxos de informação, que devem ser materializados, tornados públicos e distribuídos de acordo com as demandas dadas pelas interações sociais" (Enne, 2004: 268). En este estudio, el concepto de red, tomado como base para el desarrollo de la idea de comunidad literaria, se volvió basilar, ya que posibilitó enfatizar las movilidades culturales que engendran las estéticas locales.
} 
A partir de tales propuestas, se ha considerado, en este estudio, la novela memorial Solo queda saltar como una expresión literaria glocal. La trayectoria de las dos narradoras, Celia e Isolina incorpora la pluralidad y la diferencia engendradas por los procesos de movilidad transcultural migratoria. Por medio de la transmisión memorial, la estructura narrativa centrada en el proceso de conciencia de sí y del mundo de las dos hermanas revisita una memoria cultural más amplia, la de los inmigrantes que se han desplazado hacia el Atlántico Sur. En ese proceso, se reconoce la fuerza de las memorias individuales en la conformación de una consciencia intercultural crítica.

Los saltos realizados por las dos narradoras en búsqueda de integrarse a un linaje familiar y comunitario reflejan la importancia de las narrativas memoriales en la conformación identitaria contemporánea y demuestra el papel de las movilidades culturales en la producción literaria de María Rosa Lojo.

\section{Referencias bibliográficas}

Bernd, Zilá (2010). Dicionário de mobilidades culturais: percursos americanos. Porto Alegre: Literalis.

-------, ---- (2013). Por uma estética dos vestígios memoriais. Belo Horizonte: Fino Traço.

--- (2014), "Romance memorial ou familiar e a memória cultural; a necessidade de transmitir em Um defeito de cor, de Ana Maria Gonçalves", Revista Organon, UFRGS, nº. 57, vol. 29, jul.-dez., 2014, págs.15-27.

Bernd, Zilá y Tanira Soares (2016), "Modos de transmissão intergeraciona", Revista ALEA, Universidade Federal do Rio de Janeiro, vol. 18/3, sep.-dic., 2016, págs. 405-42.

Candau, Joël (2013). Antropologia da memória. Lisboa: Instituto Piaget.

------, --- (2014). Memória e identidade. São Paulo: Contexto.

Coelho, Maria Josele Bucco (2018), "Práticas literárias e territorialidade: estéticas glocais", en Literatura e práticas culturais: linguagens e intercâmbios. São Paulo: Pontes.

Derrida, Jacques (1973). Gramatologia. São Paulo: Perspectiva.

Eenne, Ana Lúcia S. (2004), "Conceito de rede e as sociedades contemporâneas", Revista comunicação e Informação. Goiânia: Universidade Federal de Goiás, vol.7, nº. 2, jul./dic., 2004, págs. 264-273.

Freud, Sigmund (2014). Romances familiares Livro IX. Obras Psicológicas de Sigmund Freud. Disponible en: http://www.freudonline.com.br/livros/volume-09/vol-ix-11-romances-familiares-1909-1908/

Lojo, María Rosa (2013). Leitura e escrita (entrevista online concedida a Dimas Floriani para TV UFPR, programa América Latina Viva-22 de abril de 2013). Disponible en: http://www.youtube.com/watch?v=N4FicX8SitM (2018). Solo queda saltar. Buenos Aires: Santillana.

Moisés, Massaud (1999). Dicionário de Termos Literários. $8^{\mathrm{a}}$ edc. São Paulo: Cultrix.

Oz, Amós y Fania Oz Salzberger (2015). Os judeus e as palavras. São Paulo: Companhia das Letras.

Ricoeur, Paul (2007). A memória, a história, o esquecimento. São Paulo: Editora da Unicamp.

Robin, Régine (1989). Le roman mémoriel. Montréal: Le Préambule.

Vargas Llosa, Mario (2009), "É possível pensar o mundo moderno sem o romance?", en A cultura do romance. São Paulo: Cosac Naif. 